\title{
Novo gênero e nota sinonímica em Callichromatini (Coleoptera, Cerambycidae)
}

\author{
Ubirajara R. Martins ${ }^{1,3} \&$ Dilma Solange Napp ${ }^{2,3}$
}

1. Museu de Zoologia, Universidade de São Paulo, Caixa Postal 42494, 04218-970 São Paulo, SP, Brasil.

2. Departamento de Zoologia, Universidade Federal do Paraná, Caixa Postal 19020, 81531-980 Curitiba, PR, Brasil.

3. Bolsista do CNPq.

\begin{abstract}
New genus and synonymical note in Callichromatini (Coleoptera, Cerambycidae). Cotychroma gen. nov., is described with its type-species, C. acaguassu sp. nov., from Brazil (Espírito Santo). Plinthocoelium sapphirum (Bates, 1879) is considered a new synonym of Callichroma chilensis Blanchard, 1851.
\end{abstract}

KEYWORDS. Cerambycinae, Cotychroma, new synonym, Plinthocoelium.

RESUMO. Cotychroma gen. nov., é descrito com sua espécie-tipo, C. acaguassu sp. nov., do Brasil (Espírito Santo). Plinthocoelium sapphirum (Bates, 1879) é considerado um novo sinônimo de Callichroma chilensis Blanchard, 1851.

PALAVRAS-CHAVE. Cerambycinae, Cotychroma, sinônimo novo, Plinthocoelium.

A tribo Callichromatini até o presente envolvia 10 gêneros na América do Sul (MonNé, 1993), que foram separados em oito subgêneros do gênero Callichroma Latreille, 1816, propostos por SсHMIDT (1923, 1924a, 1924b). Esses subgêneros foram elevados à categoria genérica por Podany (1965), que também propôs o subgênero Mionochroma (Schmidtianum). FRAGOSO et al. (1987) transferiram Beaveria Lane, 1970 para Callichromatini e Monné (1993) elevou Schmidtianum à categoria de gênero.

As siglas utilizadas no texto correspondem a The Natural History Museum, Londres (BMNH), Muséum National d'Histoire Naturelle, Paris (MNHN) e Museu Nacional, Universidade Federal do Rio de Janeiro, Rio de Janeiro (MNRJ).

\section{Cotychroma gen. nov.}

Etimologia. Tupi, coty $=$ ao lado de .

Espécie-tipo, Cotychroma acaguassu sp. nov.

Genas acuminadas, tão longas quanto os lobos oculares inferiores. Antenas (macho) atingem o ápice dos élitros na base do antenômero VIII. Escapo subcilíndrico, apenas anguloso no ápice externo, sem depressão basal. Antenômero III carenado; IV-X apenas expandidos no ápice externo; XI encurvado no sexto apical, com ápice rombo e com o dobro do comprimento do $\mathrm{X}$.

Tubérculo lateral do protórax desenvolvido e com ápice aguçado. Estreitamento basal do pronoto com dois sulcos. Prosterno com densa pubescência esbranquiçada na metade posterior. Mesosterno deprimido e processo prosternal abruptamente elevado e sem tubérculo. Ápice do processo mesosternal coplanar com a ponta do processo intercoxal do metasterno. Abertura glandular látero-posterior do metasterno muito evidente.

Escutelo com sulco na metade apical. Élitros com faixas estreitas de coloração metálica sutural e dorsal; friso marginal de colorido metálico. Metafêmures fusiforme-alongados, extremidades aproximam-se, mas não atingem a ponta dos élitros. Metatíbias foliáceas, com a maior largura cerca de um terço maior que a largura máxima dos metafêmures. Urosternito VI com ápice emarginado.

Discussão. Cotychroma, pelas metatíbias foliáceas, assemelha-se a Cnemidochroma Schmidt, 1924. Difere pelas antenas dos machos mais longas do que o corpo, os antenômeros IV-X apenas projetados no ápice externo, o antenômero XI curvo na ponta, com ápice rombo e com o dobro do comprimento do X; pela densa pubescência na metade posterior do prosterno; pelas faixas estreitas de colorido metálico (inclusive o friso marginal) nos élitros e pelo ápice do processo mesosternal coplanar com o ápice do processo intercoxal do metasterno, que é alargado. Em Cnemidochroma, as antenas são mais curtas que o corpo nos dois sexos, os antenômeros são fortemente expandidos no ápice externo e o XI é afilado no ápice e subigual ou apenas mais longo que o X; o prosterno é esparsamente pubescente; os élitros são destituídos de faixas de colorido metálico, exceto em $C$. ohausi (Schmidt, 1924), e o ápice do processo mesosternal é mais elevado que o processo intercoxal do metasterno, que é provido de saliência e estreitamente projetado.

\section{Cotychroma acaguassu sp. nov.}

(Fig. 1)

Macho. Colorido geral azul-esverdeado metálico; escapo esverdeado, metálico; dois terços apicais dos fêmures verde-azulados metálicos; flagelômeros, tíbias e tarsos, pretos. Tegumento recoberto por denso tomento preto principalmente no protórax e nos élitros. Região inferior da fronte e clípeo brilhantes com pontuação fina e esparsa. Regiões atrás dos lobos oculares inferiores com rugas evidentes. Gula com pêlos esparsos. Antenômero III sulcado e tricarenado. 

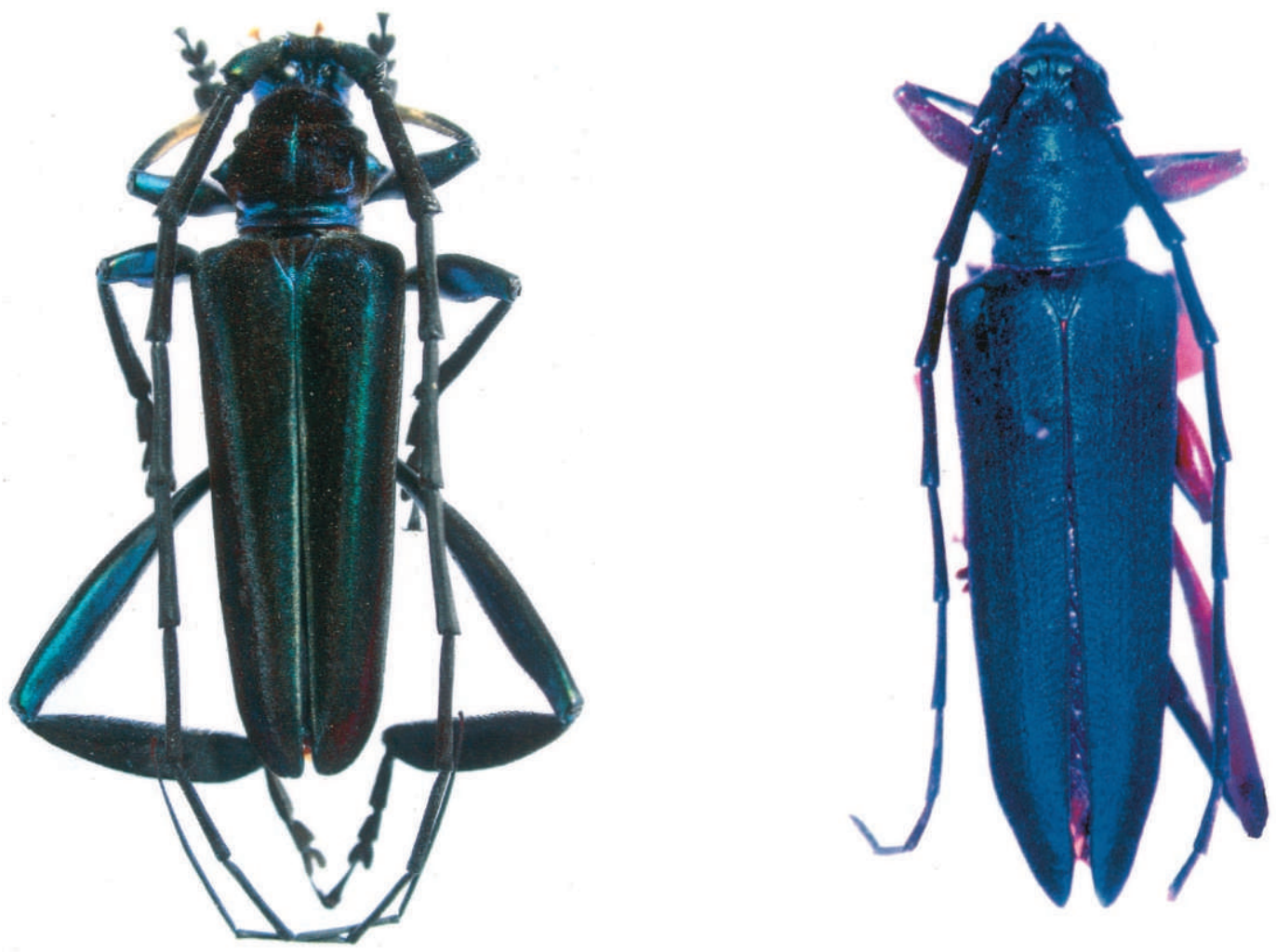

Figs. 1-2. 1, Cotychroma acaguassu sp. nov., ơ , comprimento, $26,8 \mathrm{~mm} ; 2$, holótipo 9 de Callichroma sapphira Bates, depositado no MNHN (J. S. Moure foto).

Pronoto revestido por tomento negro, exceto numa linha central longitudinal, sem rugas transversais; constrição basal revestida por tomento. Superfície dorsal dos tubérculos laterais lisa, a parte anterior (32x) finamente pontuada. Escutelo revestido por tomento, menos no sulco longitudinal. Élitros com faixa sutural estreita, revestida por pubescência esbranquiçada em quase toda a extensão; faixa dorsal mais visível na região central dos élitros. Processos intercoxais sem tubérculos. Fêmures finíssima e densamente pontuados. Metatarsômero I apenas mais longo que II+III.

Dimensões, em mm, macho. Comprimento total, 28,6; comprimento do protórax, 5,7; maior largura do protórax, 7,1; comprimento do élitro, 20,8; largura umeral, 8,4 .

Material-tipo. Holótipo ơ , BRASIL, Espírito Santo: Linhares (Reserva Biológica Sooretama), I.1963, F. M. Oliveira col. (MNRJ).

\section{Plinthocoelium chilensis (Blanchard, 1851)}

Callichroma chilensis Blanchard in GAY, 1851: 465, est. 29, fig. 2

Callichroma chilense; LACORDAIRE, 1869: 16.

Plinthocoelium chilensis; Podany, 1965: 39.

Callichroma sapphira BATES, 1879: 402. Syn. nov.

Plinthocoelium sapphirum; SCHMidT, 1924b: 386; Monné, 1993: 16 (cat.).

Callichroma plicata BAtes, 1880: 45 non LeConte, 1853.
Apenas uma espécie do gênero Plinthocoelium estava assinalada para a América do Sul: P. chilensis (Blanchard, 1851). CERDA (1986) já considerara $P$. chilensis nomina dubia e aventou a hipótese dessa espécie não pertencer à fauna chilena. VILLIERS (1972) examinou os holótipos de $P$. sapphirum e de Callichroma chilensis, mas não as considerou coespecíficas. Um dos autores (D. S. Napp) examinou novamente os holótipos dessas espécies e julgou que ambos pertencem à mesma espécie. Na realidade, $P$. sapphirum (fig. 2) ocorre no México e o gênero Plinthocoelium, aparentemente, não tem registros para a América do Sul. O trabalho de Porter (1920? que não consultamos, na realidade 1921?) apud MonNÉ (1993), menciona Callichroma chilense para o Chile (Chillán), mas é quase certo que esta citação deve estar equivocada.

Material-tipo. De Callichroma sapphira Bates, 1879: holótipo \&, descrita do México e remetido por Sallé (MNHN). De Callichroma chilensis Blanchard, 1851: holótipo O" originalmente descrita do Chile (MNHN).

Agradecimento. A Antonio Santos Silva pela execução da fotografia.

\section{REFERÊNCIAS BIBLIOGRÁFICAS}

Bates, H. W. 1879. New genera and species of Callichrominae (Coleoptera, Longicornia). Cistula Entomologica, 2:395419. 
- 1880. Biologia Centrali-Americana. Insecta, Coleoptera. London, British Museum (Natural History). v. 5, p.17-152.

Cerda, M. A. 1986. Lista sistemática de los cerambícidos chilenos (Coleoptera, Cerambycidae). Revista Chilena de Entomologia, 14:29-39.

Fragoso, S.; Monné, M. A. \& Seabra, C. A. C. 1987. Preliminary considerations on the higher classification of Cerambycinae (Coleoptera, Cerambycidae), with nomenclatural alterations. Revista Brasileira de Biologia, 47(1-2):189-202.

GAY, C. 1851. Historia física e política de Chile, Zoología, Fauna Chilena, Insectos, Coleópteros. Paris, Maulde y Renou, v. 5 , p. 285-563.

Lacordaire, J. T. 1869. Genera des Coleóptères. Paris, Roret. v. 9 (1), 409p.

Monné, M. A. 1993. Catalogue of the Cerambycidae
(Coleoptera) of the Western Hemisphere. Part VIII. São Paulo, Sociedade Brasileira de Entomologia. 97p.

PodAny, C. 1965. Remarques sur les Callichromini américains (Col., Ceramb.). Bulletin de la Société Entomologique de Mulhouse, 1965:34-41.

Schmidt, M. 1923. Bemerkungen über Callichrominen (Col., Ceramb.). Deutches Entomologisches Zeitung, 1923: $272-276$.

-. 1924a. Die amerikanischen Callichrominen (Col., Ceramb.) nach systematischen und phylogenetischen Gesichtspunkten dargestellt. Deutches Entomologisches Zeitung, 1924:297-321.

-. 1924b. Idem. Ibidem, 1924:377-396.

Villiers, A. 1972. Les types de Cerambycidae Callichromini neotropicaux du Museum de Paris. Designation de lectotypes. Bulletin de la Société Entomologique de France, 77(1-2):20-22.

Recebido em setembro de 2004. Aceito em janeiro de 2005. ISSN 0073-4721

Artigo disponível em: www.scielo.br/isz 